\title{
ACTIVE MAGNETIC BEARINGS FOR ENERGY STORAGE SYSTEMS FOR COMBAT VEHICLES
}

\author{
By: \\ M.A. Pichot \\ J.P. Kajs \\ A. Ouroua \\ B.T. Murphy \\ A. Ouroua \\ B. Rech \\ R.J. Hayes \\ J.H. Beno \\ G.D. Buckner \\ A.B. Palazzolo
}

10th EML Symposium, April 25-28, 2000, San Francisco, CA

IEEE Transactions on Magnetics, vol. 37 no. 1, January 2001, pp. 318-323

G.D. Buckner, University of North Carolina

A. B. Palazzolo, Texas A\&M University

PR - 283

Center for Electromechanics

The University of Texas at Austin

PRC, Mail Code R7000

Austin, TX 78712

(512) $471-4496$ 


\title{
Active Magnetic Bearings for Energy Storage Systems for Combat Vehicles
}

\author{
M.A. Pichot, J.P. Kajs, B.R. Murphy, A.Ouroua, \\ B.M. Rech, R.J. Hayes, and J. H. Beno \\ The University of Texas at Austin Center for Electromechanics \\ G.D. Buckner \\ North Carolina State University Department of Mechanical and Aerospace Engineering \\ A.B. Palazzolo \\ Texas A\&M University Department of Mechanical Engineering
}

\begin{abstract}
Advanced energy storage systems for electric guns and other pulsed weapons on combat vehicles present significant challenges for rotor bearing design. Active magnetic bearings (AMBs) present one emerging bearing option with major advantages in terms of lifetime and rotational speed, and also favorably integrate into high-speed flywheel systems. The Department of Defense Combat Hybrid Power Systems (CHPS) program serves as an excellent case study for magnetic bearing applications on combat vehicles. Under the sponsorship of the CHPS program, The University of Texas at Austin Center for Electromechanics (UT-CEM) has designed active magnetic bearing actuators for use in a $5 \mathrm{MW}$ flywheel alternator with a $318 \mathrm{~kg}(700 \mathrm{lb}), 20,000 \mathrm{rpm}$ rotor. The flywheel alternator serves as a power supply for multiple systems on a military vehicle, including mobility load leveling and weapons systems. Because of continuous duty requirements, magnetic bearings were chosen for this high-speed application to minimize losses and to enable the flywheel to meet a planned vehicle life of $\mathbf{1 5}$ to 25 years.

To minimize CHPS flywheel size and mass, a topology was chosen in which the rotating portion of the flywheel is located outside the stationary components. Accordingly, magnetic bearing actuators are required which share this "inside-out" configuration. Because of inherent low loss and nearly linear force characteristics, UT-CEM has designed and analyzed permanent magnet bias bearing actuators for this application. To verify actuator performance, a non-rotating bearing test fixture was designed and built which permits measurement of static and dynamic force. An active magnetic bearing (AMB) control system was designed to provide robust, efficient magnetic levitation of the CHPS rotor over a wide range of operating speeds and disturbance inputs, while minimizing the occurrence of backup bearing touchdowns. This paper discusses bearing system requirements, actuator and controller design, and predicted performance; it also compares theoretical vs. measured actuator characteristics.
\end{abstract}

Manuscript received December 21, 1999. Funding for this work was provided by the Department of Defense under contract \#4500152859, Mod 12.

\section{INTRODUCTION}

$T_{t}$ HE Combat Hybrid Power Systems (CHPS) program of the Department of Defense seeks to develop a new class of hybrid-electric combat vehicles with significant advances in the areas of mobility, armaments, and defensive systems. One of the distinguishing features of these vehicles is that all major subsystems will be electrically driven, including a hybrid electric drive-train system, electric armaments, and electromagnetic armor.

The University of Texas at Austin Center for Electromechanics (UT-CEM) is developing a flywheel alternator for this project to deliver pulsed power for weapons systems as well as load-leveling power for drivetrain components. High power electrical loads for the alternator include support for an electrothermal-chemical (ETC) gun, high-power lasers, and electromagnetic armor. The alternator also powers ac induction traction motors used for propulsion and a fully active electromagnetic suspension system. Energy storage for this machine is $25 \mathrm{MJ}$ at 20,000 rpm with an estimated mass of $595 \mathrm{~kg}(1,310 \mathrm{lb})$. It provides up to $5 \mathrm{MW}$ peak power for intermittent weapons system loads and $350 \mathrm{~kW}$ continuous power for propulsion-related loads $[1,2]$.

A cross-sectional view of the CHPS flywheel alternator is shown in Fig. 1; note that the alternator axis is oriented vertically in the vehicle. This machine consists of a vacuum housing that supports a hollow, non-rotating shaft (stator), and a magnetically levitated composite rotor. The inside-out topology shown is very efficient in terms of maximizing energy stored per unit volume, but creates challenging bearing requirements. As magnetic bearings appear to be the only type compatible with the requirements for the CHPS flywheel, development of inside-out bearing actuators and a robust control system is essential to successful flywheel design. 


\section{BEARING SYSTEM REQUIREMENTS}

In addition to dealing with rotor static and dynamic loads common to all high-speed machines, the bearing system must accommodate the terrain loads encountered by a combat vehicle over off-road terrain. To reduce windage power losses, the alternator rotor operates in a vacuum, which demands that the bearing system be vacuum-compatible. Cooling oil is available in the stator shaft at 70 to $90^{\circ} \mathrm{C}$. A summary of magnetic bearing actuator design goals appears in Table 1.

\section{BEARING SYSTEM DESIGN}

\section{A. Magnetic Bearing Type}

Permanent magnet bias homopolar (PMBH) magnetic bearings were selected for this application based on studies showing reduced power requirements and lower losses compared to heteropolar bearings [3]. An additional benefit of PMBH bearings is simplified control because of nearly linear current stiffness and positional stiffness characteristics.

Although PMBH bearings have been described in the literature previously [4], the CHPS machine presents an unusual application due to its inside-out topology. Since the rotational portion of the bearings is positioned outboard of the stator at a relatively large radius, bearing rotor laminations must withstand higher stresses than in conventional magnetic bearings. In addition, the magnetic air gap grows larger with increasing speed, instead of decreasing as occurs in bearings of conventional configuration. These factors complicate the bearing actuator design, and for our application, necessitate the use of unconventional bearing materials.

\section{B. Bearing System Configuration}

As shown in Fig. 1, the bearing configuration chosen consists of a radial magnetic bearing used on one end of the rotor and a combination bearing on the other. The radial bearing provides support in the radial direction only, while the combination bearing supports loads in both radial and axial directions.

Also incorporated in the magnetic bearing system are backup bearings. These bearings provide support during nonoperational periods when the magnetic bearings are inactive, and provide a means to shut down the machine safely in the event of a magnetic bearing system failure. In addition, the CHPS backup bearings must occasionally provide additional support for terrain shock loads (up to $8 \mathrm{~g}$ maximum) which exceed the magnetic bearing load capacity.

\section{Bearing Actuator Design}

The radial bearing actuator (Fig. 2) has an outside diameter of $36.0 \mathrm{~cm}$ (14.17 in.), an overall length of $11.0 \mathrm{~cm}$ (4.33 in.), and a radial air gap of $0.051 \mathrm{~cm}$ (0.020 in.) at rest. At 20,000 $\mathrm{rpm}$, the radial air gap increases to $0.125 \mathrm{~cm}$ (0.049 in.).

In this bearing, the bias field is established with neodymium-iron-boron ( $\mathrm{NdFeB}$ ) permanent magnets located in the center of the stator. Stator laminations are fabricated from $0.356 \mathrm{~mm}$ (0.014 in.) thick M-19 silicon steel and include dovetail-shaped coil slots to reduce rotor lamination rotating losses. A hydraulic fit is used for bearing stator assembly to the alternator shaft for both the radial and combination bearings. Silicon steel does not have adequate mechanical properties to withstand induced rotor stresses and corresponding fatigue conditions; therefore, a structural grade steel (AISI 4130) was chosen for the rotor laminations for desirable strength and fatigue characteristics, despite less desirable electromagnetic properties.

The CHPS combination bearing actuator is shown in Fig. 3. This bearing is $30.5 \mathrm{~cm}$ (12.0 in.) outside diameter with an overall length of $16.7 \mathrm{~cm}$ (6.58 in.), and radial and thrust air gaps of $0.051 \mathrm{~cm}(0.020 \mathrm{in})$ at rest. At 20,000 rpm, the radial air gap increases to $0.091 \mathrm{~cm}(0.036 \mathrm{in}$.).

\section{Actuator AnAlysis And Predicted Performance}

For actuator electromagnetic (EM) analysis, a 1-D nonlinear magnetic circuit code for inside-out actuators was developed at UT-CEM. It includes modeling of non-linear B$\mathrm{H}$ characteristics and calculations necessary for sizing of coil conductors to meet required criteria of resistance, voltage, and current. As a final check of the EM analysis, 3-D nonlinear finite element analysis (FEA) was performed.

Predicted bearing force vs. dc current is shown in Fig. 4 for the radial and combination bearings operating at 20,000 rpm. In-line and diagonal radial force curves are provided, where in-line forces are defined as being in the direction of the bearing poles, and diagonal forces in the direction of the coil slots (at $45^{\circ}$ with respect to bearing poles). To simplify control, the actuators were designed to meet stated load capacity goals while operating on the linear part of the force vs. current curve.

\section{ROTORDYNAMIC ANALYSIS}

To model rotordynamic behavior, an FEA model was developed at UT-CEM that enabled successful development of the controller. The model provides a complete analysis of natural frequencies and mode shapes in the range of 0 to $3,000 \mathrm{~Hz}$ (the controller bandwidth), and includes representation of the rotor, stator shaft, end plates, and vacuum housing.

FEA results are summarized in Table 2; natural frequencies and corresponding mode shapes are listed. The four lowest modes occur at frequencies below the minimum operating speed of 15,000 rpm, and represent rigid body modes involving no appreciable bending of either the rotor or stator. These modes must be traversed when the rotor accelerates to its operating speed range of 15,000 to 20,000 $\mathrm{rpm}$. The fact that no bending of the stator or rotor is involved means these modes can be controlled easily by the magnetic bearings.

The first flexible mode of vibration (the fundamental stator bending mode) occurs at 33,000 cpm, well above the maximum operating speed of 20,000 rpm, and will not interfere with the AMB controller as it maintains support of the rotor in its normal operating range. 


\section{BEARING ConTROLLER DEVELOPMENT}

Bearing controller development focused on single-input, single-output (SISO) approaches; accordingly, a proportional+derivative (PD) compensator was chosen as the baseline controller.

A linear stability analysis based on the control model shown in Fig. 5 was conducted for a range of proportional gains $(0 \leq \mathrm{Kp} \leq 80)$ and derivative gains $(0 \leq \mathrm{Kd} \leq 0.05)$. Based on this analysis, PD controller gains were selected and controller performance was evaluated for a variety of operating conditions. Using a proportional gain of 10 and a derivative gain of 0.03 , simulations confirmed AMB stability over the entire speed range (0 to 20,000 rpm). This PD controller was robust to modest values of mass imbalance and sensor runout, but the required AMB coil voltages were excessive, and the controller was particularly sensitive to sensor noise and disturbances.

To address these deficiencies, a controller refinement called "imbalance compensation" was implemented $[5,6]$. Imbalance compensation introduces a cascaded band-reject notch filter (whose center frequency tracks the rotor speed) to attenuate controller responses to synchronous disturbances. In other words, mass imbalance and synchronous runout are not controlled, which enables the rotor to spin about its inertial axis (instead of controlling it to spin about is geometric axis). Assuming adequate air gap exists, the rotor no longer transmits imbalance forces to the stator/housing (vibration and noise are reduced) and synchronous control effort is virtually eliminated.

Unfortunately, the introduction of a tracking notch filter had an undesirable impact on overall system stability. To counteract this effect, a series of fixed-frequency notch filters and a lead compensator were systematically cascaded with the existing controller, as shown in Fig. 6. The resulting cascaded controller demonstrated acceptable performance over the operating range for a larger range of disturbances and noise.

\section{CONTRol System Performance EVAluation}

An extensive series of dynamic simulations was conducted to assess system performance for a variety of operating conditions and disturbance inputs. The simulations confirmed the control system effectiveness with respect to design objectives. Most importantly, the cascaded design maintained stable levitation of the CHPS rotor over the entire speed range (0 to 20,000 rpm) for a variety of disturbance inputs, including sensor runout, mass imbalance, sensor noise, and inertial loading (due to vehicle cornering and braking). Additionally, peak coil voltages and currents were within the specified limits for the selected power amplifiers, and adequate margin against saturation in the flux path circuit was achieved. Finally, these simulations provided valuable design specifications for the power amplifiers, sensors, and machining tolerances.

\section{Bearing Actuator Test Hardware}

UT-CEM fabricated and assembled a radial bearing actuator for testing in order to verify design and analysis codes and to provide first-hand experience with fabrication and operation of the inside-out bearing actuators. The radial test bearing stator appears in Fig. 7. To measure bearing characteristics, a non-rotating test fixture was designed and built which permitted direct measurement of output force, displacement, coil temperature, and air gap flux density levels. An illustration of the radial bearing test fixture is shown in Fig. 8. For measuring bearing output forces, eight strain-gauge type force transducers were provided; for measuring displacements of the bearing rotor with respect to the stator, four eddy current type displacement sensors were used. Thin Hall sensors were procured that allow direct measurement of magnetic air gap flux densities. The experimental setup is shown in Fig. 9.

\section{Test Results}

Radial bearing actuator parameters were measured with gaps corresponding to zero-speed and full-speed conditions at room temperature. (Two rotor assemblies with different air gap dimensions were provided.) Results are summarized below.

\section{A. Positional Stiffness Measurement}

Predicted vs. measured positional stiffness is shown in Fig. 10. Measured stiffness for the zero-speed gap is $123 \mathrm{kN} / \mathrm{cm}$ (70 lb/mil), compared to $63.1 \mathrm{kN} / \mathrm{cm}$ (36 lb/mil) for the fullspeed gap. As expected, this actuator exhibits highly linear positional stiffness.

\section{B. Output Force Measurement}

Output force as a function of dc and ac actuator current is plotted in figures 11 and 12. Bearing design and initial force predictions were based on a lamination packing factor (PF) of 93\% (the PF predicted by the lamination vendor); however, FEA results match measured results better if a $98 \% \mathrm{PF}$ is assumed. Further study is required, therefore, to determine the actual PF and to determine the reason why 98\% PF must be used in the FEA code to produce good agreement with measured results.

In Fig. 12, force vs. current is plotted for ac current at 50 Hz. As seen by comparing Figs. 11 and 12, the current stiffness (force per unit current) is significantly greater for dc than for ac current input. This characteristic (which is predicted by the FEA code) is also seen in the transfer function plot of Fig. 14. These force measurements demonstrate that the actuator meets stated load capacity requirements and exhibits nearly linear behavior.

\section{Air Gap Flux Density Measurement}

Hall sensors were inserted into the bearing air gap to measure the bias flux density distribution. Predicted and measured field distributions as a function of circumferential angle and axial length are plotted in Fig. 13 for the zerospeed air gap condition. The predicted field levels are plotted for a 98\% PF, which gives good agreement with experimental results. 


\section{Transfer Function Measurement}

Current stiffness magnitude and phase angle vs. frequency are plotted in Fig. 14 for actuator currents of 1 and $5 \mathrm{~A}$. Measurements were limited to a maximum frequency of 200 $\mathrm{Hz}$ to avoid bearing fixture natural frequency modes above $200 \mathrm{~Hz}$. Two transfer function plot characteristics are especially noteworthy: the current stiffness magnitude at dc is substantially greater than that measured above $50 \mathrm{~Hz}$, and a consistent $20^{\circ}$ phase lag was measured between input current and output force. Knowledge of the phase lag is particularly valuable for accurate control system modeling. Eddy current and magnetic hysteresis behavior in the various bearing components are most likely responsible for the measured phase lag.

\section{CONCLUSIONS}

UT-CEM has designed an active magnetic bearing system for use in a flywheel alternator for a hybrid-electric combat vehicle. The alternator and magnetic bearing actuators incorporate an inside-out topology in which rotating components are located radially outboard of the stationary components. An SISO controller was successfully designed to provide robust bearing control under simulated conditions. A prototype radial bearing was successfully fabricated, assembled, and tested in a bearing test fixture that directly measures critical bearing parameters. Knowledge gained from this work is an important step in the successful implementation of active magnetic bearings for combat vehicle energy storage systems.

\section{REFERENCES}

[1] M. Pichot, J. Kajs, R. Hayes, J. Beno, A. Ouroua, and B. Rech, "InsideOut Configuration Active Magnetic Bearing Actuators," 5th International Symposium on Magnetic Suspension Technology, Dec 13, 1999.

[2] G. Buckner, A. Palazzolo, J. Kajs, B. Murphy, and J. Beno, "Control System for Inside-Out Configuration Magnetic Bearings," 5th International Symposium on Magnetic Suspension Technology, Dec 13, 1999.

[3] M. Kasarda, P. Allaire, P. Norris, C. Mastrangelo, and E. Maslen, "Experimentally Determined Rotor Power Losses in Homopolar and Heteropolar Magnetic Bearings," International Gas Turbine \& Aeroengine Congress \& Exhibition, Stockholm, Sweden, June 2-5, 1998, ASME Publication No.98-GT-317.

[4] G. Schweitzer, H. Bleuler, and A. Traxler, Active Magnetic Bearings: Basics, Properties, and Applications of Active Magnetic Bearings, vdf Hochschulverlag AG an der ETH Zurich, 1994.

[5] R. Herzog, B. Philipp, G. Conrad, and L. Rene, "Unbalance Compensation Using Generalized Notch Filters in the Multivariable Feedback of Magnetic Bearings," IEEE Transactions on Control Systems Technology, Vol. 4, No. 5, pp. 580-586, September 1996.

[6] C.R. Knospe, "Stability and Performance of Notch Filter Controllers for Unbalance Response," Proceedings of the International Symposium on Magnetic Suspension Technology, NASA Langley Research Center, Hampton VA 1991.

[7] B. Murphy, J. Beno, and D. Bresie, "Bearing Loads in a Vehicular Flywheel Battery,” 1997 SAE International Congress and Exposition, Feb 24-27, 1997, Detroit, MI.

[8] H. Bleuler, "Decentralized Control of Magnetic Bearing Systems," Dissertation, Eidgenössische Technische Hochschule, Zürich, 1984 (Diss. ETH Nr. 7573).

\section{TABLE TITLES}

TABLE 1. MAGNETIC BEARING ACTUATOR DESIGN GOALS TABLE 2. ROTORDYNAMIC FEA RESULTS

\section{Figure CAPTIONS}

Fig. 1. CHPS flywheel alternator

Fig. 2. Radial bearing actuator

Fig. 3. Combination bearing actuator

Fig. 4. Predicted actuator force vs. dc current

Fig. 5. Linear model of baseline PD control system

Fig. 6. Final cascaded bearing controller

Fig. 7. Radial test bearing stator

Fig. 8. Radial bearing test fixture

Fig. 9. Bearing test experimental hardware

Fig. 10. Measured positional stiffness

Fig. 11. Actuator force vs. dc current, predicted vs. measured

Fig. 12. Measured actuator force vs. ac current

Fig. 13. Zero-speed air gap flux density distribution, predicted vs. measured

Fig. 14. Measured zero-speed actuator transfer function

Table 1. Magnetic bearing actuator design goals

Table 2. Rotordynamic FEA results 